\title{
In vivo imaging and quantitative analysis of insulin-receptor interaction in lean and obese Zucker rats
}

\author{
J.C.Sodoyez ${ }^{1 *}$, F.Sodoyez-Goffaux ${ }^{2}$, S. Treves ${ }^{2}$, C. R. Kahn ${ }^{1}$ and R.von Frenckell ${ }^{3}$ \\ ${ }^{1}$ Research Division, Joslin Diabetes Center and ${ }^{2}$ Division of Nuclear Medicine, Children's Hospital Medical Center, Harvard Medical School, \\ Boston, Massachusetts, USA and ${ }^{3}$ Department of Psychiatry, University of Liege, Liege, Belgium
}

\begin{abstract}
Summary. Imaging and quantitative analysis of insulin-receptor interaction was studied in vivo in lean and obese Zucker rats, using a recently developed technique in which purified Tyr A14 ${ }^{123} \mathrm{I}$-monoiodoinsulin is intravenously injected and the tracer followed by scintillation scanning. The obese rats were $72 \%$ overweight, had near normal blood glucose concentrations and an 11-fold increase in plasma insulin concentration. In both groups of rats, the tracer was rapidly taken up by the liver (by a receptor mediated mechanism) and the kidneys (by a non-receptor mediated process). Past this maximum, radioactivity decreased in both organs as ${ }^{123}$ I-insulin was degraded and free ${ }^{123}$ I-iodide was released into the plasma compartment. Heart radioactivity (i.e. blood pool) mirrored that of the liver and kidneys. The rapid initial decrease of blood radioactivity was concomitant with liver and kidney uptake of ${ }^{123}$ I-insulin. Release of free iodide from these organs induced a slow secondary rise of blood radioactivity followed by a final decline corresponding to clearance of plasma iodide, mainly by urinary excretion. Liver radioactivity profiles of
\end{abstract}

lean and obese rats were parallel. When expressed per $\mathrm{g}$ weight, liver radioactivity was significantly decreased in obese rats. However, due to hepatomegaly in obese rats, total liver radioactivity was significantly higher in homozygous $\mathrm{fa} / \mathrm{fa}$ rats than in lean littermates. Furthermore, if the marked hyperinsulinaemia of the obese rats is taken into account, total bound insulin was enhanced in the liver of $\mathrm{fa} / \mathrm{fa}$ rats whatever reference is used, either $\mathrm{g}$ weight or total liver. The kidney profile of radioactivity of both rats was not significantly different. In conclusion: (1) obese rats are insulin resistant as near normal glycaemia is achieved at the price of a marked hyperinsulinaemia; (2) liver uptake of insulin is enhanced in obese rats, and (3) the insulin resistance syndrome of $\mathrm{fa} / \mathrm{fa}$ rats is not due to a decrease in liver insulin receptor number and/or affinity but rather to as yet unknown event(s) subsequent to receptor binding.

Key words: ${ }^{123}$ I-Insulin, Zucker rats, receptors, scintillation scanning, computer analysis.
In 1961, Zucker and Zucker described a syndrome of obesity, hyperinsulinaemia and hyperlipaemia in rats, that is inherited as an autosomal recessive mutation [1]. In homozygous $\mathrm{fa} / \mathrm{fa}$ rats, the syndrome becomes visible after weaning with hyperinsulinaemia being one of the earliest signs [2]. The affected rats are hyperphagic [3], lose their normal pattern of nocturnal feeding [4], rapidly accumulate fat mainly in their subcutaneous tissue and display a low level of spontaneous activity [5]. Pancreatic B cell hyperplasia and hypertrophy are present [6] and in vitro, islet tissue releases massive amounts of insulin $[7,8]$. Together with adiposity and hyperinsulinaemia, a syndrome of insulin resistance appears. Insulin binding to isolated soleus muscle has been shown

\footnotetext{
* Present address: Department of Internal Medicine, University of Liege, Hôpital de Bavière, 66 Boulevard de la Constitution, B-4020 Liege, Belgium
}

to be decreased [9], while that to hepatocytes has been more variable with some studies indicating a decreased binding $[10,11]$ or mildly decreased binding [12] or no change [13], especially when investigations were performed on young rats (10-15-week old). In the present study, we have applied a new technique involving ${ }^{123} \mathrm{I}$ labelled insulin and scintillation scanning [14] to study insulin kinetics and half-life in vivo in this animal model of obesity and insulin resistance.

\section{Materials and methods}

Twenty to 25 week-old lean ( $\mathrm{fa} /-$ ) and obese (fa/fa) female Zucker rats were obtained from Dr. M. Greenwood (Vassar College, Poughkeepsie, New York, USA). All had free access to a standard laboratory diet until the time of the experiment. The rats were anaesthetized with pentobarbital $(60 \mathrm{mg} / \mathrm{kg}, \mathrm{IP})$ and a PE 50 polyethylene tube was introduced into a jugular vein. 
Purified bovine insulin $(0.1 \mathrm{mg})$ was labelled with ${ }^{123} \mathrm{I}(5 \mathrm{mCi})$ and the species monoiodinated on Tyr A14 rapidly purified by high pressure liquid reverse phase chromatography using a technique described previously (theoretical spec. act. $\equiv 41 \mathrm{mC} / \mu \mathrm{g}$, assuming ${ }^{123} \mathrm{I}$ had $100 \%$ radiochemical purity and was totally carrier-free) [14].

Rats were laid in the prone position on the converging collimator of a Large Field of View Scintillation camera (Searle, Des Plaines, Illinois, USA) connected to a Gamma 11 computer (Digital Equipment Corporation, Maynard, Massachusetts, USA). ${ }^{123} \mathrm{I}-$ Insulin $(30-60 \mu \mathrm{Ci}$, based on theoretical spec. act., $0.73-1.46 \mathrm{ng}$ ) was injected IV as a boIus at time zero. Kinetic data were recorded in zoom mode, in a $64 \times 64$ matrix. Frame rate was one $/ 5 \mathrm{~s}$ for the first $5 \mathrm{~min}$ and one $/ 30 \mathrm{~s}$ for the following $25 \mathrm{~min}$. At the end of the $30-\mathrm{min}$ recording period, blood was drawn by heart puncture, the liver, kidneys and stomach were rapidly dissected, the weights of the liver and kidneys were measured and a static frame of the carcass and isolated liver, kidneys and stomach was taken.

Using a radioisotope calibrator (Capintec, Ramsey, New Jersey, USA), the actual injected radioactivity $(\mu \mathrm{Ci})$ was measured by counting the activity of the ${ }^{123} \mathrm{I}$-insulin contained in the syringe before and after the IV injection. Using the static frame taken at minute 30 , the apparent radioactivity of the isolated kidneys, liver and stomach and of the remaining carcass (cpm) was measured and the sum of these values was taken as $100 \%$ of injected radioactivity. The respective percentages of radioactivity in the liver and kidneys at $30 \mathrm{~min}$ were calculated.

A $3 \times 3$ cells region of interest was defined over the right upper part of the liver. This location was selected to eliminate the influence of radioactivity in the aorta and vena cava on the one hand, and of the right kidney on the other hand. After subtraction of background taken over the hip, the liver time-activity curve was obtained and calibrated by using the actual percentage of radioactivity in the liver at $30 \mathrm{~min}$.

A $4 \times 2$ cells region of interest was similarly defined over the lower pole of each kidney. This location was selected to minimize the influence of partially superimposed organs, mainly the liver and stomach. After subtraction of background taken under the lower pole of each kidney, a time-activity curve was obtained and its ordinate calibrated by using the actual percentage of radioactivity in the kidneys at $30 \mathrm{~min}$.

A $4 \times 2$ cells region of interest was also defined over the heart and the time-activity curve of this region was taken as representative of blood radioactivity.

Blood glucose and plasma immunoreactive insulin measurements were kindly performed by Dr. Soeldner (EP Joslin Diabetes Center, Boston, Mass) using the glucose oxidase method and the double-antibody immunoprecipitation method with a porcine insulin standard.

\section{Statistical analysis}

The BMD P2V program of analysis of variance of repeated measures was employed to test the difference between two groups and the interaction between groups and time [15]. When analyzing liver data, a first run of the program showed a high correlation between cell means and standard deviations. Log transformation of the data reduced this correlation to 0.0477 and 0.0910 respectively, when liver radioactivity was expressed per g weight of tissue or per whole organ. Having satisfied the criteria of homoskedasticity, a standard Snedecor test was applied.

In the case of the kidneys, even after $\log$ transformation, a weak correlation still existed between the mean of the log of the variables and their standard deviation $(r=0.41)$. The Huynh-Feldt test was applied [16] with decreased number of degrees of freedom.

The Student's t-test also was used to compare unpaired data.

\section{Results}

The biological characteristics of the animals studied are summarised in Table 1 . The body weight of the obese
Table 1. Biometrical characteristics of lean $(\mathrm{Fa} /-)$ and obese $(\mathrm{fa} / \mathrm{fa})$ Zucker rats

\begin{tabular}{|c|c|c|c|c|c|c|}
\hline \multirow[b]{2}{*}{ Body weight (g) } & \multicolumn{2}{|c|}{ Lean rats } & \multicolumn{3}{|c|}{ Obese rats } & \multirow{2}{*}{$\frac{p}{<0.001}$} \\
\hline & 240 & $\begin{array}{l} \pm 31 \\
(6)\end{array}$ & 413 & \pm & & \\
\hline Liver weight (g) & & $2 \pm 1.18$ & & $\frac{5 \pm}{(7)}$ & 0.88 & $<0.001$ \\
\hline Kidneys weight (g) & & $\begin{array}{l}6 \pm 0.22 \\
(6)\end{array}$ & & $\begin{array}{l}5 \pm \\
(7)\end{array}$ & 0.12 & $<0.001$ \\
\hline $\begin{array}{l}\text { Blood glucose } \\
\text { concentration }(\mathrm{mmol} / \mathrm{l})\end{array}$ & & $\begin{array}{l}7 \pm 1.08 \\
(6)\end{array}$ & & \pm & 1.37 & NS \\
\hline $\begin{array}{l}\text { Plasma IRI concen- } \\
\text { tration }(\mathrm{mU} / \mathrm{l})\end{array}$ & 37 & $\begin{array}{l} \pm 8 \\
(6)\end{array}$ & 400 & $\begin{array}{l} \pm 2 \\
(8)\end{array}$ & & $<0.001$ \\
\hline
\end{tabular}

Results are expressed as mean \pm SD with number of observations in parentheses
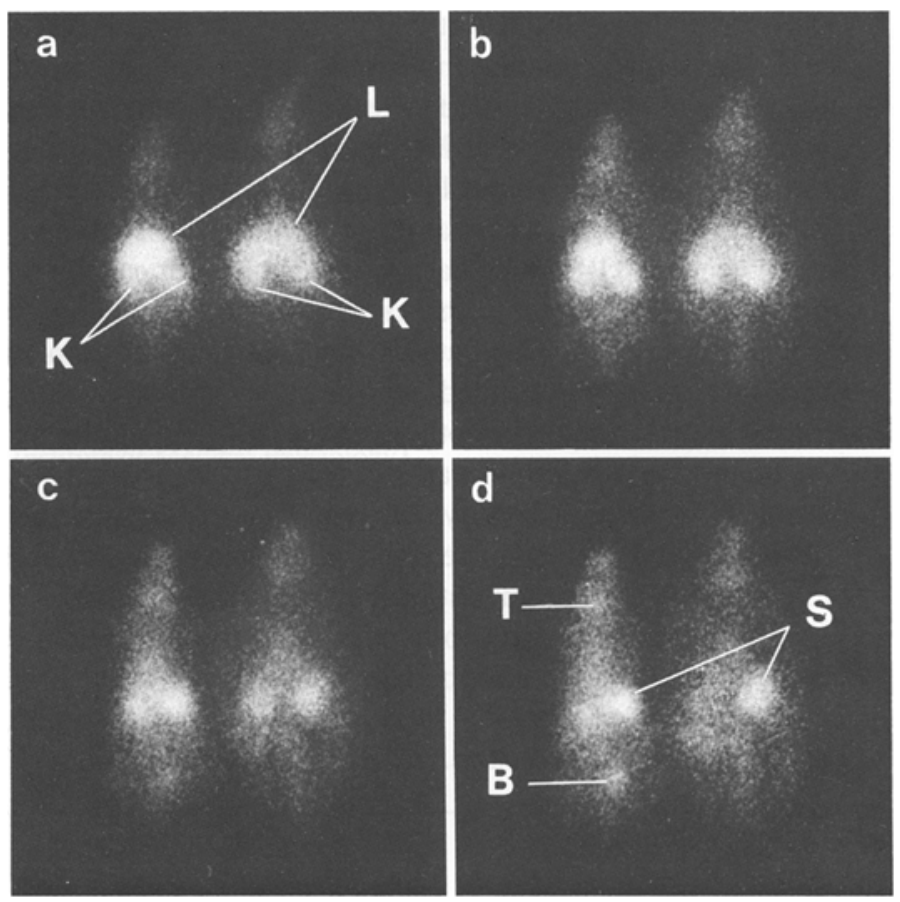

Fig.1a-d. Anterior views taken $3 \mathrm{~min}(\mathbf{a}), 10 \mathrm{~min}(\mathbf{b}), 20 \mathrm{~min}(\mathbf{c})$ and $30 \mathrm{~min}$ (d) after IV injection of ${ }^{123} \mathrm{I}$-insulin at time zero. The lean rat is on the lefthand side of the field. $\mathrm{L}=$ liver, $\mathrm{K}=$ kidney, $\mathrm{S}=$ stomach, $\mathrm{B}=$ bladder and $\mathrm{T}=$ thyroid.

animals was $72 \%$ above that of lean littermates. In obese rats, liver weight was doubled and kidney weight was increased by $30 \%$. The average blood glucose concentration was higher in obese animals, but the difference was not statistically significant. By contrast, the fa/ fa rats were markedly hyperinsulinaemic, consistent with an insulin resistant state. Their plasma had a milky appearance, due to hyperlipaemia and particularly to the well known increase in very low density lipoproteins [17].

For each pair of rats studied, sequential scintigraphic images were taken at 3,10,20 and $30 \mathrm{~min}$ and an example of such images is shown in Figure 1. Early 

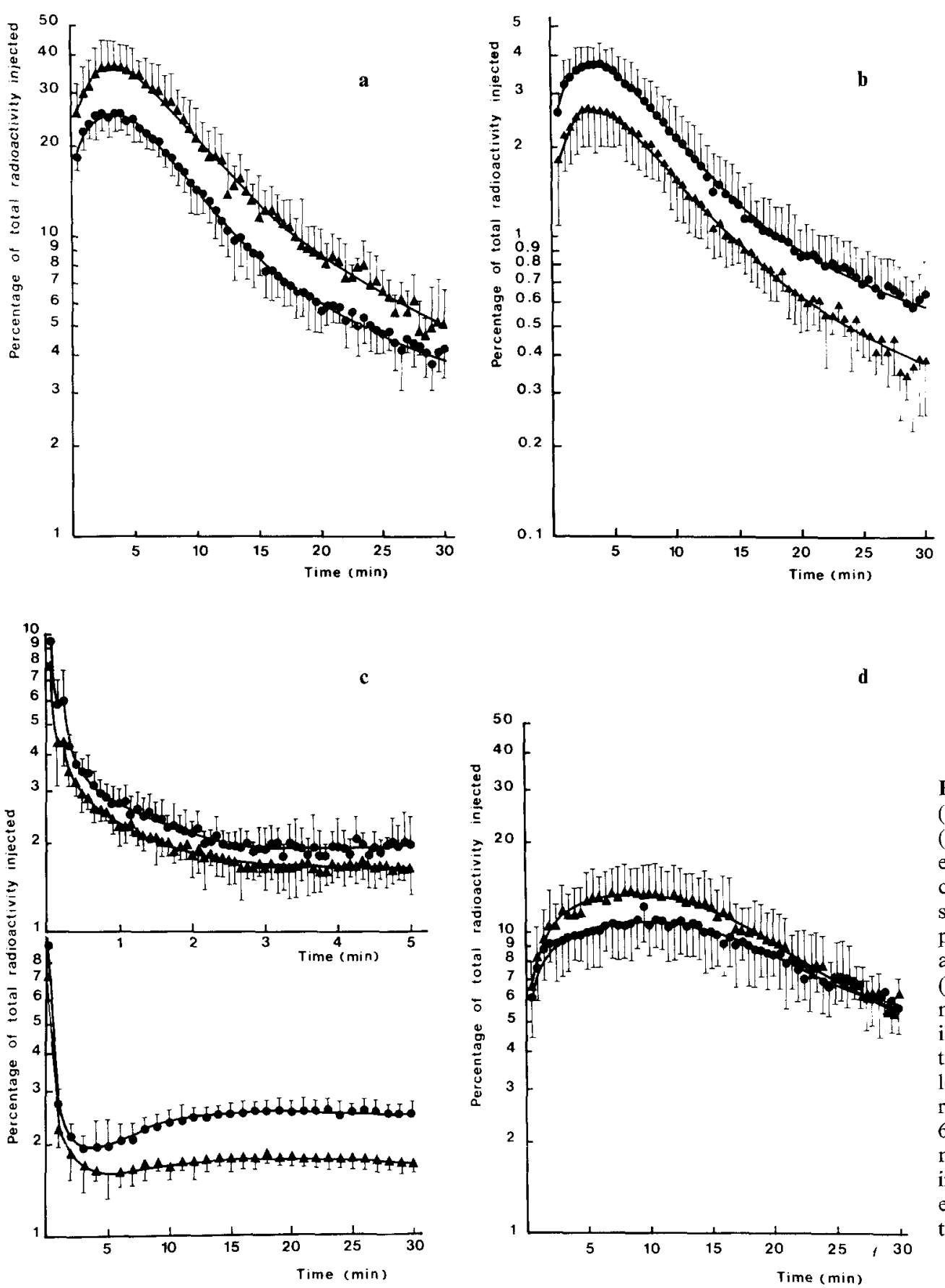

Fig. 2 a -d. Time-activity curve of liver $(\mathbf{a}, \mathbf{b})$, heart (c) and kidneys (d) of lean $(-)$ ) and obese ( $-\mathbf{\Lambda}$ ) rats. Liver radioactivity was expressed as percentage of total radioactivity $\left({ }^{123} \mathrm{I}\right.$-insulin) injected per whole liver (a) or per $g$ liver (b) and kidney radioactivity as percentage of total radioactivity ( ${ }^{123}$ I-insulin) injected per both kidneys. Heart activity (c, upper panel) illustrates early variations of radioactivity (one measurement $/ 5 \mathrm{~s}$ ) and (c, lower panel) the results of the 30-min recording period (one measurement/ $60 \mathrm{~s}$ ). All resuits are expressed as mean \pm SD. Number of lean rats: six in panels $\mathbf{a}, \mathbf{b}$ and $\mathbf{c}$ and eight in panel d. Number of obese rats: seven throughout

images ( 3 and $10 \mathrm{~min}$ ) were essentially the same for each of the studied pairs and for both types of rats. They indicate early uptake of ${ }^{123}$ I-insulin by the liver and kidney (Fig. 1 a) followed by a decrease of radioactivity in both organs as ${ }^{123}$ I-insulin is degraded and free ${ }^{123} \mathrm{I}$-iodide is released into the plasma. Late images essentially reflect free iodide biodistribution (Fig. 1 $\mathrm{c}$ and d). The pair illustrated in Figure 1 was selected because it best illustrates a difference of free iodide biodistribution between lean and obese animals. Indeed, in this example, the bladder of the lean rat is already visible after $20 \mathrm{~min}$, whereas that of the obese rat is still not detectable after $30 \mathrm{~min}$. In the lean rat, despite urinary iodide loss, the stomach is much more radioactive than that of the obese littermate.

As we have shown previously, receptor-mediated uptake can be estimated using this technique by following liver radioactivity $[14,18]$. The log of liver radioactivity (percentage of total injected) was expressed either per whole organ (Fig. 2a) or per g weight of tissue (Fig. 2b). In both lean and obese animals, hepatic uptake was rapid, reaching a maximum between 3 and $4 \mathrm{~min}$. When expressed per $\mathrm{g}$ of liver, the time-activity curve for the obese animals was parallel $(\mathrm{F}=1.17$; $p=0.1855$ ) and significantly lower than that of the lean rats $(\mathrm{F}=10.06 ; p=0.0089)$. On average, the uptake of 
insulin by liver of obese rats was reduced $40 \%$ when expressed per $g$ of tissue. By contrast, when radioactivity profiles of whole liver were compared, the time-activity curves remained parallel $(\mathrm{F}=1.20 ; p=0.1532)$ but the curve of the obese animal was higher $(F=19.66$; $p=0.001$ ). This is a reflection of the massive hepatomegaly present in the obese rats.

The kidney uptake of ${ }^{123} \mathrm{I}$-insulin was slower than hepatic uptake, reaching a maximum at $10 \mathrm{~min}$ (Fig. 2d). In obese rats, kidney uptake was slightly higher than that in lean rats. However, the two curves were not statistically different $(\mathrm{F}=1 ; p=0.3397)$ and using the Huynh test, there was no interaction with time $(\mathrm{F}=1.70 ; p=0.1544)$.

Heart (i.e. blood) radioactivity profile of obese and lean rats is shown in Figure $2 \mathrm{c}$. Initial decrease of blood radioactivity during the first $3 \mathrm{~min}$ was quite comparable in both types of rats. Blood radioactivity reached a minimum at $3 \mathrm{~min}$ in control rats, and this was followed by an increase as radioactivity re-entered the plasma compartment as free iodide. This secondary rise of plasma radioactivity was delayed and less marked in the obese rats.

Gastric radioactivity at $30 \mathrm{~min}$ was $10.95 \pm 2.75 \%$ (mean \pm SD) of the total injected in lean rats and $6.94 \pm 1.94 \%$ in obese animals. The difference was statistically different $(p<0.05)$.

\section{Discussion}

Over the past 10 years, it has become clear that in a variety of insulin resistant states, there is an alteration in the insulin-receptor interaction as measured using techniques in vitro and cells taken from the animal. Recently, we have described a new technique which allows us to study the insulin-receptor interaction and the fate of insulin in intact animals. This technique depends on labelling insulin with ${ }^{123} \mathrm{I}$ to a very high specific activity (theoretical value $41 \mathrm{mCi} / \mu \mathrm{g}$ ) and following the labelled insulin by using a scintillation scanner. In previous studies, we showed that the most prominent uptake occurred by the liver, which reached a maximum in 3-4 min and was about $30 \%$ of the total injected dose. This uptake appears to be receptor-mediated and can be blocked by injection of excess unlabelled insulin [14] or by antibodies to the insulin receptor [18]. Renal uptake represented about $15 \%$ of the total injected dose, but did not appear to be receptor mediated, and actually increased when hepatic uptake was blocked by insulin or anti-receptor antibody $[14,18]$. In the present study, we have applied this technique to study insulin biokinetics and receptor interaction in the Zucker obese rat.

We have found that insulin biokinetics in the Zucker fatty rat is, in general, similar to that in its lean littermate. There appears to be a difference in ${ }^{123} \mathrm{I}$-insulin uptake by liver of the obese rat, but the difference de- pends on whether binding is expressed per g weight of liver or per whole liver. In the former case, maximum liver radioactivity in obese rats was decreased by $30 \%$, whereas in the latter case, it was increased by $36 \%$ in obese rats compared with thin littermates. Thus, while there seems to be a modest decrease in ${ }^{123}$ I-insulin uptake per $\mathrm{g}$ of tissue in this model of obesity, this is more than compensated for by the increase in liver size in the obese rats. Furthermore, the decrease in ${ }^{123} \mathrm{I}$-insulin uptake is also compensated for by endogenous hyperinsulinaemia. If peripheral plasma IRI is taken into account, the liver of obese Zucker rats has a great deal more insulin bound, whatever reference is used. Indeed, at $3 \mathrm{~min}$, the ratio of total insulin bound per $\mathrm{g}$ of liver of obese to lean rat

(percent of radioactivity per $\mathrm{g}$ of obese liver $\times$ plasma IRI concentration in obese rats percent of radioactivity per $g$ of lean liver $\times$ plasma IRI concentration in lean rats

was 7.6 whereas, when uptake was expressed per whole liver, the ratio was 13.6. These ratios should be taken as indicative only, as we did not verify that the ratios of plasma IRI concentration in obese and lean rats were the same in portal as in peripheral plasma. In addition, because insulin half life in the liver was the same in both animals, the overall flux of insulin through the hepatocyte of obese animals was markedly enhanced. This conclusion that hepatic flux of insulin is markedly increased in obesity is not in contradiction with in vitro observations that insulin receptor number is normal or slightly decreased. Firstly, total receptor number as defined by Ro in the Scatchard plot is much greater than the number of receptors occupied in the presence of physiological insulin concentration. As a consequence, bound insulin markedly increases if cells or membranes are exposed to an insulin concentration which is 11-fold higher than the physiological one. Thus, also in vitro, even if there was a modest decrease in Ro, cells or membranes isolated from obese rats and exposed to insulin concentrations usually achieved in $\mathrm{fa} / \mathrm{fa}$ rats would bind more insulin than their lean counterpart exposed to lean rat insulin concentration. Secondly, in vivo, hepatic insulin flux depends upon other factors than Ro and $K_{d}$, among which is hormone delivery to the liver, i.e. hepatic blood flow.

We have observed previously in normal rats that there is an inverse relationship between hepatic and renal insulin uptake. In the obese Zucker rat, kidney uptake of ${ }^{123} \mathrm{I}$-insulin was slightly, but not significantly, increased; this is similar to the effect of an injection of a small amount of anti-insulin receptor antibody [18] and suggests that more insulin is available to the kidney, possibly reflecting a decrease in the functional extrahepatic receptor compartment or its partial saturation by the high plasma insulin levels. Taking into account the high plasma IRI in the obese rats, the overall amount of insulin retained by the kidneys was 11 -fold higher in obese rats than in lean littermates. This observation is consistent with that of Eng and Yalow who 
found more radioimmuno-assayable insulin in the kidneys of obese mice [19].

It is now believed that plasma insulin clearance rate partly reflects the size of the receptor compartment [20-22]. In the present study, the initial rate of decrease of plasma radioactivity was at least as high in obese rats as in lean littermates. The two plasma radioactivity curves become divergent after the third minute, a time at which free ${ }^{123}$ I-iodide appears in the plasma and later becomes the prominent radioactive species [21]. Between 10 and $30 \mathrm{~min}$, plasma ${ }^{123} \mathrm{I}$-iodide concentration was significantly lower in obese rats. Inspection of Figure $2 \mathrm{a}$ and $\mathrm{d}$ indicates that the release of radioactivity by the liver and kidney is not retarded in obese rats. Less ${ }^{123} \mathrm{I}^{-}$was accumulated by the stomach and excreted in the urine (Fig. 1d). Other authors have shown that iodide uptake was also decreased in the thyroid gland [23]. From the above considerations, the most likely explanation is that ${ }^{123} \mathrm{I}$-iodide distribution volume was larger in obese than in lean rats.

In conclusion, the obese Zucker fatty rat is insulin resistant as near normal glycaemia is achieved at the price of an 11-fold increase in plasma IRI concentration. This high plasma IRI concentration reflects an increased insulin flux as more hormone is produced by the pancreatic B cells and more is taken up and degraded by the liver and kidney. In the obese mutant, insulin resistance is not due to a decrease in liver insulin receptors, but rather to a yet unknown abnormality of post-receptor binding events. Whether conclusions reached with this animal model must be restricted to it or are also applicable to other types of obesity and particularly in man remains to be determined.

Acknowledgments. This work was supported by grants from the National Fund for Scientific Research, Brussels, Belgium. The authors are indebted to C.J. De Vos for preparing the illustrations and to M. Fodor for secretarial assistance.

\section{References}

1. Zucker LM, Zucker TF (1961) Fatty, a new mutation in the rat. J Hered 52: 275-278

2. Zucker LM, Antoniades HN (1972) Insulin and obesity in the genetically obese rat 'fatty'. Endocrinology 90: 1320-1330

3. Bray GA, York DA (1972) Studies on food intake of genetically obese rats. Am J Physiol 223: 176-179

4. Becker EE, Grinker JA (1977) Meal patterns in the genetically obese Zucker rat. Physiol Behav 18: 685-692

5. Stern JS, Johnson PR (1977) Spontaneous activity and adipose cellularity in genetically obese Zucker rat (fa/fa). Metabolism 26: 371-380

6. Shino A, Matsuo T, Iwatsuka I, Suzuoki Z (1973) Structural changes of pancreatic islets in genetically obese rats. Diabetologia 9: $413-421$
7. Stern JS, Johnson PR, Greenwood M, Zucker L, Hirsch J (1972) Insulin resistance and pancreatic insulin release in the genetically obese Zucker rat. Proc Soc Exp Biol Med 139: 66-69

8. Stern JS, Johnson PR, Batchelor B, Zucker L, Hirsch J (1975) Pancreatic insulin release and peripheral tissue resistance in Zucker obese rats fed high and low carbohydrate diets. Am J Physiol 228: $543-548$

9. Crettaz M, Prentki M, Zaninetti D, Jeanrenaud B (1980) Insulin resistance in soleus muscle from obese Zucker rats. Involvement of several defective sites. Biochem J 186: 525 -534

10. Mahmood HA, Wood PJ, Marks V (1978) The effect of induced hyperglucagonemia on the Zucker fatty rat. Diabetologia 14: 405-412

11. Steele NC, Martin RJ, Baile CA (1979) Insulin receptor characteristics and insulin degradation by Zucker lean and obese rats. Horm Metab Res 11: 525-526

12. Broer Y, Freychet P, Rosselin G (1977) Insulin and glucagon-receptor interactions in the genetically obese Zucker rat: studies of hormone binding and glucagon-stimulated cyclic AMP levels in isolated hepatocytes. Endocrinology 101: 236-249

13. Clark JB, Keen S, Clarck CM Jr (1982) Studies on the regulation of insulin binding by liver plasma membranes from Zucker fatty rats. Diabetes 31:867-873

14. Sodoyez JC, Sodoyez-Goffaux F, Guillaume M, Merchie G (1983) Study of ${ }^{123}$ I-insulin metabolism in normal rat and man using external detection by a scintillation camera. Science 219:865-866

15. Dixon WJ, Brown MB (eds) (1981) BMDP Biomedical Computer Programs. University of California Press, Berkley, Los Angeles, London

16. Huynh H (1978) Some approximate tests for repeated measures designs. Psychometrika 43:161-175

17. Schonfeld G, Felski C, Howald M (1974) Characterization of plasma lipoproteins of the genetically obese hyperlipoproteinemic Zucker fatty rats. J Lipid Res 15: 457-464

18. Sodoyez JC, Sodoyez-Goffaux F, Treves S (1983) ${ }^{123}$ I-Insulin metabolism in animal models of insulin resistance syndromes: effect of antibodies to the insulin-receptor and obesity. Diabetes 32 (Suppl 1): $43 \mathrm{~A}$

19. Eng J, Yalow RS (1980) Insulin recoverable from tissues. Diabetes 29: $105-109$

20. Zeleznik AJ, Roth J (1978) Demonstration of the insulin receptor in vivo in rabbits and its possible role as a reservoir for the plasma hormone. J Clin Invest 61: 1363-1374

21. Sodoyez JC, Sodoyez-Goffaux FR, Moris YM (1980) ${ }^{125}$ I-Insulin: kinetics of interaction with its receptors and rate of degradation in vivo. Am J Physiol 239: E3-E11

22. Philippe J, Halban PA, Gjinovci A, Duckworth WC, Estreicher J, Renold AE (1981) Increased clearance and degradation of $\left({ }^{3} \mathrm{H}\right)$ insulin in streptozotocin diabetic rats. Role of the insulin receptor compartment. J Clin Invest 67: 673-680

23. York DA, Hershman JM, Utiger RD, Bray GA (1972) Thyrotropin secretion in genetically obese rats. Endocrinology 90: 67-72

Received: 8 July 1983

and in revised form: 22 December 1983

Dr. J.C. Sodoyez

Department of Internal Medicine

University of Liege

Hôpital de Bavière

66 Boulevard de la Constitution

B-4020 Liege, Belgium 